\title{
Multi-criteria Approach for Prioritizing Bridge Maintenance in Developing Country (Case Study of Bali Province, Indonesia)
}

\author{
Putu Alit Suthanaya ${ }^{1, *}$, Ida Bagus Artamana ${ }^{1}$ \\ ${ }^{1}$ Engineering Faculty, Udayana University \\ Jalan Kampus Bukit Jimbaran (Bali, Indonesia) \\ *Corresponding author's email: suthanaya [AT] rocketmail.com
}

\begin{abstract}
Transport agencies in developing countries are often faced by the need to maintain a lot of road projects but have limited budget. One important road infrastructure complement is bridge. The bridge is a vital infrastructure facilities for the continuing development of social and economic activities of the region. A serious problem in developing countries such as Indonesia is limited funds available for maintenance. In Bali Province, the priority of bridge maintenance program is prepared based only on the technical condition of the bridge. However, many aspects actually need to be considered. As limited funds available, the objective of this study is to develop bridge maintenance prioritization criteria and rank the bridges to be maintained based on the Analytic Hierarchy Process (AHP) method by using Bali Province as a case study. It was found that the stakeholders for bridge maintenance in Bali Province gave priority to road network system 1.34 times more than movement system, 1.56 times more than land use system and 2.49 times more than institutional system. The road network system was identified as the main factor considered in maintaining bridge in Bali Province. From 86 bridges considered in this study, it was found that 19 bridges were in the very high priority category. It was also found that the ranking of bridge maintenance priority based on the AHP method was very similar to the realized program.
\end{abstract}

Keywords- AHP, multi-criteria, priority, bridge maintenance

\section{INTRODUCTION}

The national road network is developed through regional development approach in order to achieve balance and equitable development across the country, establish and strengthen national unity to strengthen national defense and security. The road also forms the spatial structure in order to achieve national development goals. The road network is functioning properly if the road pavement and amenities complement are properly maintained. One important road infrastructure complement is bridge. The bridge is a vital infrastructure facilities for the continuing development of social and economic activities of the region. Along with the age of the bridge, the more tenuous conditions of service of a bridge. To keep and maintain the condition of the bridge to remain in functional condition, it is necessary to perform maintenance. Maintenance of the bridge consists of routine maintenance, periodic maintenance, rehabilitation and replacement of bridges. A serious problem in developing countries such as Indonesia is limited funds available for maintenance.

Transport agencies in developing countries often have many road projects within very limited budget. Therefore, road projects need to be ranked and then selected starting from the top of the list. In order to overcome budget limitation in developing countries, the road projects need to be prioritize based on the clear and transparent decision making process [1]. According to [2], in the process of analyzing solutions to infrastructure development in urban areas, several criteria need to be considered. Usually, the analysis incorporates economic criteria and monetary measures. A study conducted in the City of Tshwane evaluated several methods for prioritizing transport infrastructure projects [3]. The study found that cost/benefit analysis is not suitable for this purpose as it is focused only on economic efficiency without considering other aspects such as social and environmental impacts which are difficult to be valued in monetary terms. Similar study also found that cost benefit analysis only is not sufficient to be applied to prioritize transport projects [4]. Various aspects influence road project prioritization and therefore require multi-criterion analysis.

Since various aspects need to be considered in prioritizing road projects, the decision making process is very complex [5]. Application of multicriteria analysis is needed in order to accommodate various vision of the decision maker which include Department of Public Work, Department of Transport, Legislative Body, NGo, Public, etc. [6]. Mathematical models need to be developed for the road projects prioritization by considering also economic, social and environmental aspects [7]. In the study in Lithuania, several factors for road projects prioritization such as net present value (NPV), 
internal rate of return (IRR), payback period (PI), noise reduction, dust reduction and importance of the road for public transport were considered [7].

There are many multi criteria analysis methods available for road projects prioritization, however five most suitable methods identified include REGIME, ELECTRE family, analytical hierarchy process (AHP), multiple attribute utility approach (MAUT), and ideal point approach (ADAM method). Analytic Hierarchy Process (AHP) was found to satisfy almost all criteria evaluated [4]. Multi-citeria analysis (MCA) has been widely applied in the transport sector, for example in the urban transport projects prioritization. MCA was applied to prioritize nine urban transport projects in the Tianjin Binhai New Area, China by considering five criteria such as economic, engineering, environmental, social and risk [1]. MCA was also used to asses variants of the integrated system of urban public transport (ISUPT) in Cracow, Poland by considering economic, technical, environmental and social aspects [8]. Another study in Poland has applied the AHP and ELECTRE III/IV methods to evaluate 18 urban transport projects. The study claimed that AHP and ELECTRE III/IV methods gave satisfactory results to generate rankings of transport projects [9]. Similar study has also been conducted in Madurai City, India and the AHP was used in the selection of urban transport system (metro rail, mono rail and bus) to be implemented [10]. MCA has not only been used to prioritize urban transport projects, but also to prioritize the location of transport facility such as planning multi-storage garages in Croatia. The study considered four criteria include traffic, economic, environmental and social criteria [11].

Within the transport sector, MCA has also been used to prioritize several alternative land corridors for a road development in Alpine Valley in Northern Italy [12]. Five different environmental components potentially affected by the space requirement were considered: vegetation; wildlife habitat; landscape; land production; and geomorphology. MCA was also applied for an integrated and preventive evaluation of rural road projects in Belgium at the design stage. Safety, economic and environmental factors were considered in this study [13]. Another study in Netherlands has assessed the relative importance of barriers for Carbon Capture and Storage (CCS) deployment of the road projects using AHP dan the Decision Making Trial and Evaluation Laboratory (DEMATEL) methods [14]. They recommended that multicriteria analysis considering economic, legal, social and technical aspects needs to be applied in the ranking of the barriers. Another study has applied MCA to rank the road to be repaired and maintained in Banten Province, Indonesia. Several criteria included such as road type, status, capacity, damage level and economic aspect [15]. The AHP was also used to select appropriate financing method of four public private partnership (PPP) methods for highway projects in Iran [16]. Recent study used Fuzzy AHP to evaluate the safety of mine road in Huang Mailing phosphate rock, China [17]. Previous studies indicated that MCA was found very useful for road projects prioritization.

Study on the application of MCA to prioritize bridge maintenance priority is limited. A study used Fuzzy AHP method to evaluate durability of reinforced concrete arch bridge in China [19]. Another study used AHP to develop remedial model of Bateman's Bay Bridge on the South Coast of NSW. Three criteria considered include safety, functionality and sustainability [19]. Since 1993, the Indonesian Ministry of Public Works and Public Housing through the Directorate General of Highways has developed a system for inspection, record keeping, planning, investigation, design, and supervision of bridge called Bridge Management System (BMS). The priority of bridge maintenance program is prepared based only on the technical condition of the bridge. Highest priority is given to the bridge which is technically in the worst condition. However, if several bridges are technically in similar condition, there will be problem in establishing priorities, because only one criterion used in the preparation of priority. There are about 86 bridges with the length of $215.86 \mathrm{~km}$ within the national road network in Bali Province. As limited funds available, the objective of this study are to develop bridge maintenance prioritization criteria, rank the bridges to be maintained based on AHP method, compare to the existing method (based only on technical condition of the bridge) and realized bridge maintenance program.

\section{ANALYTIC HIERARCHY PROCESS (AHP)}

The Analytic Hierarchy Process (AHP) can be used to understand a complex problem of decision making based on a hierarchical structure [20]. The Analytic Hierarchy Process (AHP) is an effective method to prioritize projects based on a set of decision making criteria [21]. Every decision maker may have different criteria weights. The criteria weights can be determined based on objective and subjective approaches. Criteria weights for the objective approaches can be derived from available technical data. Criteria weights for the subjective approaches are derived from decision maker's subjective judgment [6].

In the AHP, decision makers can construct a multi attribute decision making problem in at least three levels of attribute hierarchy. The first level is the target or goal, multiple criteria that influence the goal attainment is in the second level and the third level describes the competing alternatives. Each criterion considered is weighted based on decision maker's perception and opinion on that criterion. A high value of weight will be given to the more important criterion. The score is calculated for each alternative for a certain criterion. Higher score indicates better performance of an alternative project for a certain criterion. In order to rank the road projects, the total score is calculated by combining the criteria weight and the alternative scores. The total score for an alternative road projects is a weighted sum of scores by 
considering all criterion [21]. The steps of the AHP includes determination of the vector of criteria weights, determination of the matrix of alternative scores and prioritization of the alternative projects.

In the AHP, the relative weightings between several alternatives are obtained based on decision maker's judgment on the relative importance of two criteria. The pairwise comparison matrix is developed based on the decision maker's judgment. The scale used for pairwise comparison can be seen in Table 1 [22].

Table 1: The scale for pairwise comparison between two criteria

\begin{tabular}{|c|c|c|}
\hline $\begin{array}{l}\text { Intensity of } \\
\text { importance }\end{array}$ & Definition & Explanation \\
\hline 1 & Equal & The two criteria have the same contribution to the objective \\
\hline 3 & Weak & One criteria is slightly over the other \\
\hline 5 & Moderate & One criteria is preferred than the other \\
\hline 7 & Strong & One criteria is strongly preferred than the other \\
\hline 9 & Very strong & One criteria is very strongly preferred than the other \\
\hline $2,4,6,8$ & $\begin{array}{l}\text { For interpolation between the } \\
\text { above values }\end{array}$ & $\begin{array}{l}\text { A compromise judgment numerically because there is no good } \\
\text { word to describe it }\end{array}$ \\
\hline
\end{tabular}

The vector of criteria weights is obtained from the pairwise comparison matrix. A reciprocal matrix is calculated based on Equation 1. The matrix contains the derived pairwise comparison, aij $=w i / w j$ (wi and $w j$ are the relative importance of criteria $i$ and $j$, respectively), their reciprocals, aji $=1 / a i j$, and unity as its diagonal elements $a j i=1$. If the two criteria are equally important, the value is 1 . If one criteria is more important than the other, the value is $>1$. On the other hand, if one criteria is less important than the other, then the value is $<1$ [21].

$A=\left[\begin{array}{cccc}a_{11} & a_{l 2} & \ldots & a_{l n} \\ a_{2 l} & a_{22} & \ldots & a_{2 n} \\ \vdots & \vdots & \ldots & \vdots \\ a_{n l} & a_{n 2} & \ldots & a_{n n}\end{array}\right]=\left[\begin{array}{cccc}1 & w_{l} / w_{2} & \ldots & w_{l} / w_{n} \\ w_{2} / w_{l} & 1 & \ldots & w_{2} / w_{n} \\ \vdots & \vdots & \ldots & \vdots \\ w_{2} / w_{l} & w_{n} / w_{2} & \ldots & 1\end{array}\right]$

If we multiply matrix $A$ with vector of weights, $W$, therefore $A W=n W$ (a system of homogenous linear equations) where $w$ is termed as a principal right eigenvector of $A$ and $n$ is therefore the eigenvalue of $A$ [21]:

$(A-n I) W=0$.

or

$A w=\left[\begin{array}{cccc}1 & w_{l} / w_{2} & \ldots & w_{l} / w_{n} \\ w_{2} / w_{l} & 1 & \ldots & w_{2} / w_{n} \\ : & \vdots & \ldots & \vdots \\ w_{n} / w_{l} & w_{n} / w_{2} & \ldots & 1\end{array}\right]\left[\begin{array}{c}w_{l} \\ w_{2} \\ \vdots \\ w_{n}\end{array}\right]=n\left[\begin{array}{c}w_{l} \\ w_{2} \\ \vdots \\ w_{n}\end{array}\right]=n w$

The decision maker's judgments are rarely consistent, therefore the eigenvalue of $A$ equal to $n$ is also rarely happen. The largest eigenvalue ( $\lambda$ max) will be always greater than or equal to $n$ and equation 2 is transformed to [21]:

$$
\begin{gathered}
A W=\lambda_{\max } \mathrm{W} \\
w_{i}=\frac{\left(\prod_{j=1}^{n} a_{i j}\right)^{1 / n}}{\sum_{k=1}^{n}\left(\prod_{j=1}^{n} a_{k j}\right)^{1 / n}}
\end{gathered}
$$

And

$$
\lambda_{\max }=\sum_{i=1}^{n}\left\{\left(\sum_{j=1}^{n} a_{i j}\right) \times w_{i}\right\}
$$


The degree of inconsistency of matrix $A$ can be measured based on the value of $\lambda \max$ and $n$. If the value of $\lambda \max$ closer to $n$ indicates that matrix $A$ is more consistent. Calculation of Consistency Index $(\mathrm{CI})$ of the matrix $\mathrm{A}$ is given in Equation 5 [21].

$$
C I=\frac{\left(\lambda_{\max }-n\right)}{(n-1)}
$$

The Random Consistency Index (RI) as shown in Table 2 is used to determine the acceptance of the CI value [21]. RI is the average CI of a randomly generated reciprocal matrices (500 sample size) with dimension $n$. Based on the value of $\mathrm{CI}$ and RI, the degree of inconsistency (Consistency Ratio or CR) of the matrix A can be calculated. The value of CR $\leq 0.1$ indicates that the matrix is accepted with sufficient consistency. However, if $\mathrm{CR}>0.1$ indicates that the inconsistency is too large and unacceptable, and therefore the decision makers must re-check their judgments.

Table 2: The Random Consistency Index (RI)

\begin{tabular}{ccccccccccc}
\hline $\mathrm{n}$ & 1 & 2 & 3 & 4 & 5 & 6 & 7 & 8 & 9 & 10 \\
\hline $\mathrm{RI}$ & 0 & 0 & 0,58 & 0,9 & 1,12 & 1,24 & 1,32 & 1,41 & 1,45 & 1,49 \\
\hline
\end{tabular}

\section{METHODOLOGY}

National road in Bali Province considered in this study consists of 37 road segments with total length of $215.86 \mathrm{~km}$ and complemented with 86 bridges. Figure 1 shows the national road network in Bali Province and Table 3 provides the location, number and length of the bridges. Based on the AHP approaches, this study followed three stages process, i.e. developing the structural hierarchy, weighting each criteria based on pair wise comparison matrix, and determining ranking of alternatives. The structure hierarchy consist of three levels, i.e. the goal (level 1), criterion (level 2) and subcriterion (level 3).

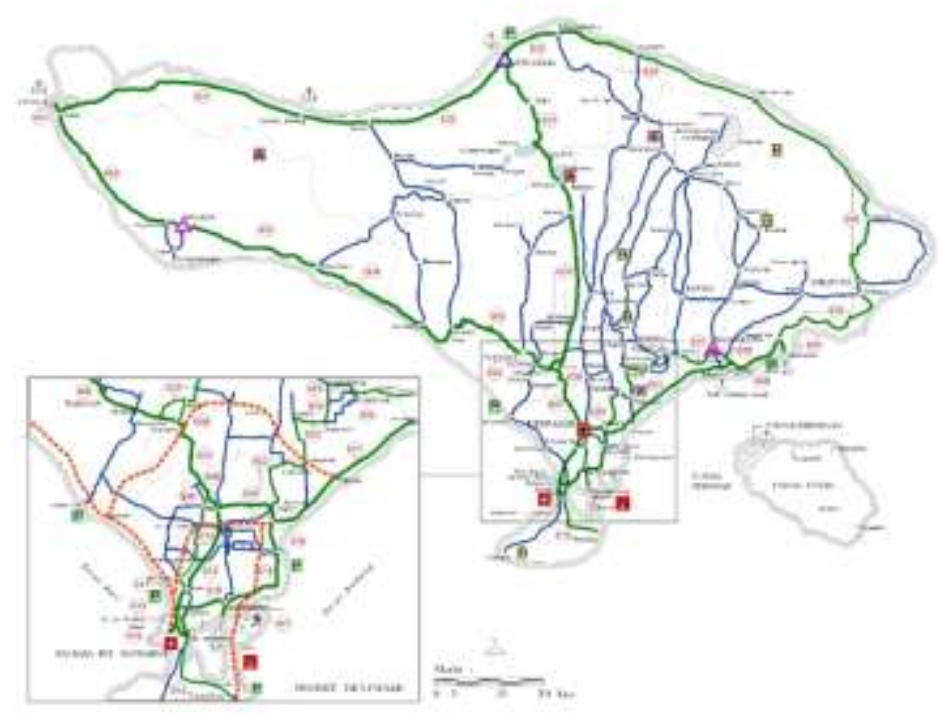

Figure 1: National Road Network in Bali Province

Table 3: National bridge in Bali Province

\begin{tabular}{llcr}
\hline No & Region & Number of bridges & \multicolumn{1}{c}{ Length $(\mathrm{m})$} \\
\hline 1 & Badung & 8 & 218.6 \\
\hline 2 & Buleleng & 3 & 44.8 \\
\hline 3 & Denpasar & 17 & 539.6 \\
\hline 4 & Gianyar & 45 & $1,567.3$ \\
\hline 5 & Tabanan & 7 & 467.1 \\
\hline 6 & Klungkung & 6 & 749.0 \\
\hline & Total & 86 & $3,586.4$ \\
\hline
\end{tabular}


Hierarchy structure level-1 for this study is the goal (to prioritize the bridges to be maintained). Hierarchical structure level-2 consisted of four criteria that contribute to the goal (road network system (A), institutional system (B), land use system (C), and movement system (D)). At hierarchy level-3, each of the criteria in level 2 was divided further into several sub-criteria. The criterion road network system was divided into the bridge condition (a1), bridge function (a2) and bridge material (a3). The criterion institutional system was divided into budget allocation (b1), inclusion in the bridge strategic planning (b2), and bridge maintenance history (b3). The criterion land use system was divided into transportation strategic area (c1), tourism strategic area (c2) and socio-cultural strategic area (c3). The criterion group movement system was influenced by traffic volume (ADT) (d1) and road narrowing (d2).

In order to obtain the decision maker's judgment on the importance of one criterion over the other, a questionnaire was developed and distributed to 34 respondents. The respondents were selected based on purposive sampling method considering their involvement in decision making for prioritizing bridge maintenance in Bali Province.

\section{RESULTS AND DISCUSSION}

\subsection{Criteria Comparison}

There were four criteria compared in the second level which included road network system (A), institutional system (B), land use system (C), movement system (D). The pairwise comparison matrix at this level is shown in Table 4. The Eigen vector for criteria $A(\rho A)$ was calculated by normalizing each column of the matrix (for example, $\rho \mathrm{A}=1.00 \times 2.76$ $\mathrm{x} 1.42 \times 1.32=5.21)$. The results for $\rho \mathrm{B}, \rho \mathrm{C}$ and $\rho \mathrm{D}$ are listed in Table 4 . The weight $(\mathrm{W})$ among the criteria compared was then calculated by averaging the entries on each row. For example, WA $=4 \sqrt{5.21}=1.51$. The results of WB, WC and WD are shown in Table 4. Furthermore, the relative weight of each criterion (Xi) was determined by dividing the weight of each criteria (Wi) with $\sum \mathrm{Wi}$. For example XA $=1.51 / 4.21=0.358$. The results of analysis at level 2 indicated that the road network system (A) as the main factor that influence the prioritization of bridge projects in Bali Province with XA value of 0.358 . The other factors are movement system (D) with WD value of 0.268 , followed by land use system (with $\mathrm{XC}=0.230$ ), and institutional system with $\mathrm{XB}$ value 0.144 . The priority to road network system was $35.8 / 26.8=1.34$ times more than movement system, 1.56 times more than land use system and 2.49 times more than institutional system. The value of the Eigen maximum $(\boldsymbol{\lambda} \max )$ was obtained based on calculation as follow: $\boldsymbol{\lambda}$ max $\mathrm{A}$ $=(1.00 \times 0.358)+(2.76 \times 0.144)+(1.42 \times 0.230)+(1.32 \times 0.268)=1.438$. The IC $=(4.007-4) /(4-1)=0.0024$. As there were 4 criterion considered, $\mathrm{RI}=0.9$, therefore, $\mathrm{CR}=0.073 / 0.9=0.003<10 \%$. As $\mathrm{CR}$ value $<0.1$ indicates that the result was consistent.

Table 4: Criteria comparison matrix (level-1)

\begin{tabular}{ccccccccc}
\hline Criteria & $\mathrm{A}$ & $\mathrm{B}$ & $\mathrm{C}$ & $\mathrm{D}$ & $\rho i$ & $W i$ & $X i$ & $\lambda$ max \\
\hline $\mathrm{A}$ & 1.00 & 2.76 & 1.42 & 1.32 & 5.21 & 1.51 & 0.358 & 1.438 \\
\hline $\mathrm{B}$ & 0.36 & 1.00 & 0.66 & 0.56 & 0.14 & 0.61 & 0.144 & 0.577 \\
\hline $\mathrm{C}$ & 0.70 & 1.51 & 1.00 & 0.83 & 0.88 & 0.97 & 0.230 & 0.921 \\
\hline $\mathrm{D}$ & 0.76 & 1.77 & 1.20 & 1.00 & 1.61 & 1.13 & 0.268 & 1.071 \\
\hline$\Sigma$ & & & & & & 4.21 & 1.000 & 4.007 \\
\hline
\end{tabular}

\subsection{Sub-criteria comparison}

\subsubsection{Comparison at the third level (level 3a)}

There were 3 sub-criteria considered at this level i.e. bridge condition (a1), bridge function (a2) and bridge material (a3). The most important factor identified was bridge condition (a1) with X(a1) value of 0.663 , followed by bridge function and bridge material (see Table 5). The bridge condition was given priority $66.3 / 14=4.74$ times more than bridge material and 3.37 times more than bridge function.

Table 5: Sub criteria comparison at the third level (3a)

\begin{tabular}{cccccccc}
\hline Criteria & $\mathrm{a} 1$ & $\mathrm{a} 2$ & $\mathrm{a} 3$ & $\rho \mathrm{i}$ & $W i$ & $X i$ & $\chi \max$ \\
\hline $\mathrm{a} 1$ & 1.00 & 3.98 & 4.00 & 15.95 & 2.52 & 0.663 & 2.008 \\
\hline $\mathrm{a} 2$ & 0.25 & 1.00 & 1.67 & 0.42 & 0.75 & 0.197 & 0.597 \\
\hline $\mathrm{a} 3$ & 0.25 & 0.60 & 1.00 & 0.15 & 0.53 & 0.140 & 0.423 \\
\hline$\Sigma$ & & & & & 3.80 & 1.000 & 3.029 \\
\hline
\end{tabular}




\subsubsection{Comparison at the Third Level (3b)}

Table 6 shows sub-criteria comparison matrix for level-3 (3b). Three criteria considered include budget allocation (b1), inclusion in the bridge strategic planning (b2) and bridge maintenance history (b3). The most important factor among the three criteria is criterion b3 (bridge maintenance history) with $\mathrm{X}(\mathrm{b} 3$ ) value of 0.444 . The next factor is budget allocation (b1) and inclusion in the bridge strategic planning (b2). The importance of bridge maintenance history is $44.4 / 28.7=1.55$ times more than budget allocation and 1.19 times more than the inclusion of the bridge in the strategic planning.

Table 6: Sub-criteria comparison at the third level (3b)

\begin{tabular}{cccccccc}
\hline Criteria & $\mathrm{b} 1$ & $\mathrm{~b} 2$ & $\mathrm{~b} 3$ & $\rho \mathrm{i}$ & $W i$ & $X i$ & $\lambda \max$ \\
\hline $\mathrm{b} 1$ & 1.00 & 1.16 & 0.60 & 0.69 & 0.88 & 0.287 & 0.864 \\
\hline $\mathrm{b} 2$ & 0.87 & 1.00 & 0.66 & 0.57 & 0.83 & 0.269 & 0.808 \\
\hline $\mathrm{b} 3$ & 1.67 & 1.53 & 1.00 & 2.55 & 1.37 & 0.444 & 1.334 \\
\hline$\Sigma$ & & & & & 3.08 & 1.00 & 3.006 \\
\hline
\end{tabular}

\subsubsection{Comparison at the Third Level (3c)}

There were four criteria considered at this level include transportation strategic area (c1), tourism strategic area (c2) and socio-cultural strategic area (c3). The highest weight is obtained for criterion $\mathrm{c} 1$ (transportation strategic area) with $\mathrm{X}(\mathrm{c} 1)$ value of 0,539 , followed by criterion $\mathrm{c} 3$ (socio-cultural strategic area) and criterion c2 (tourism strategic area) (see Table 7). The stakeholders for provincial bridge maintenance in Bali Province gave priority to transportation strategic area 53.9/22.7=2.37 times more than tourism strategic area. Based on this results, it was identified that transportation strategic area is the main criteria in the bridge maintenance prioritization. The tourism strategic area is only accounted for $22.7 \%$ of the total score. The value of the $\lambda \max$ is 3.008 , therefore, IC $=(3.008-3) /(3-1)=0,0039$. The value of RI $=$ 0.58 , therefore, $\mathrm{CR}=0.0039 / 0.58=0.0067<10 \%$ (indicates consistent result).

Table 7: Sub-criteria comparison at the third level (3c)

\begin{tabular}{cccccccc}
\hline Criteria & $\mathrm{c} 1$ & $\mathrm{c} 2$ & $\mathrm{c} 3$ & $\rho \mathrm{i}$ & $W i$ & $X i$ & $\lambda$ max \\
\hline $\mathrm{c} 1$ & 1.00 & 2.60 & 2.11 & 5.48 & 1.76 & 0.539 & 1.622 \\
\hline $\mathrm{c} 2$ & 0.38 & 1.00 & 1.06 & 0.41 & 0.74 & 0.227 & 0.682 \\
\hline $\mathrm{c} 3$ & 0.47 & 0.94 & 1.00 & 0.45 & 0.77 & 0.234 & 0.704 \\
\hline$\Sigma$ & & & & & 3.27 & 1.00 & 3.008 \\
\hline
\end{tabular}

\subsubsection{Comparison at the Third Level (3d)}

Sub-criteria considered at this level include traffic volume/ADT (d1) and road narrowing (d2). The results of pairwise comparison is shown in Table 8. Stakeholders for national road maintenance in Bali Province gave higher weight on criterion $\mathrm{d} 2$ (road narrowing) with $\mathrm{X}(\mathrm{d} 2)$ value of 0,597 , followed by criterion $\mathrm{c} 1$ (traffic volume/ADT. The criterion road narrowing is more important 59.7/40.3=1.48 times more than traffic volume. Therefore, road narrowing is identified as the main factor to contribute to the bridge maintenance priority at this level. Traffic volume is accounted for $40.3 \%$ of the total score.

Table 8: Sub-criteria comparison at the third level (3d)

\begin{tabular}{ccccccc}
\hline Criteria & $\mathrm{d} 1$ & $\mathrm{~d} 2$ & $\rho \mathrm{i}$ & $W i$ & $X i$ & $\lambda$ max \\
\hline $\mathrm{d} 1$ & 1.00 & 0.68 & 0.68 & 0.82 & 0.403 & 0.81 \\
\hline $\mathrm{d} 2$ & 1.48 & 1.00 & 1.48 & 1.22 & 0.597 & 1.19 \\
\hline$\Sigma$ & & & & 2.04 & 1.00 & 2.00 \\
\hline
\end{tabular}

\subsection{Recapitulation of the quantitative value for each criterion}

Table 9 shows the weight for each criteria considered to determine the bridge maintenance priority in Bali Province. The bridge condition was found to be the most important criterion followed by road narrowing, transportation strategic area, traffic volume, bridge function, bridge maintenance history, socio-cultural strategic area, tourism strategic area, bridge material, budget allocation and inclusion in strategic planning. The weight of each criterion was then applied to rank the road segments. Mathematical formulae to prioritize bridge maintenance in Bali Province is $\mathrm{Y}=23.74(\mathrm{a} 1)+$ $7.05(\mathrm{a} 2)+5.01(\mathrm{a} 3)+4.13(\mathrm{~b} 1)+3.87(\mathrm{~b} 2)+6.39(\mathrm{~b} 3)+12.4(\mathrm{c} 1)+5.22(\mathrm{c} 2)+5.38(\mathrm{c} 3)+10.61(\mathrm{~d} 1)+16.19(\mathrm{~d} 2)$. 
Table 9: The weight for each criterion

\begin{tabular}{rlrrr}
\hline \multirow{2}{*}{ No } & Criteria & $\begin{array}{c}\text { Analysis } \\
\text { Code }\end{array}$ & Weight & $\begin{array}{c}\text { Conversion } \\
\text { x 1000 }\end{array}$ \\
\hline 1 & Bridge condition & $\mathrm{a} 1$ & $23.74 \%$ & 237.4 \\
\hline 2 & Bridge function & $\mathrm{a} 2$ & $7.05 \%$ & 70.5 \\
\hline 3 & Bridge material & $\mathrm{a} 3$ & $5.01 \%$ & 50.1 \\
\hline 4 & Budget allocation & $\mathrm{b} 1$ & $4.13 \%$ & 41.3 \\
\hline 5 & Inclusion in strategic planning & $\mathrm{b} 2$ & $3.87 \%$ & 38.7 \\
\hline 6 & Bridge maintenance history & $\mathrm{b} 3$ & $6.39 \%$ & 63.9 \\
\hline 7 & Transportation strategic area & $\mathrm{c} 1$ & $12.40 \%$ & 52.2 \\
\hline 8 & Tourism strategic area & $\mathrm{c} 2$ & $5.22 \%$ & 53.8 \\
\hline 9 & Socio-cultural strategic area & $\mathrm{c} 3$ & $5.38 \%$ & 106.1 \\
\hline 10 & Traffic volume (ADT) & $\mathrm{d} 1$ & $10.61 \%$ & 162.0 \\
\hline 11 & Road narrowing & $\mathrm{d} 2$ & $16.19 \%$ & 1000 \\
\hline & T O T A L & & $100,00 \%$ & \\
\hline
\end{tabular}

Table 10 shows the top ten rank of priority for bridge maintenance in Bali Province. In total, based on percentile method, there were 19 bridges identified in the very high priority class, 16 bridges in the high priority, 19 bridges in medium class, 15 bridges in low category and 17 bridges in very low priority class.

Table 10: Bridge maintenance priority (top ten)

\begin{tabular}{|c|c|c|c|c|c|c|c|c|c|c|c|c|c|c|}
\hline \multirow{2}{*}{ Rank } & \multirow{2}{*}{ Bridge Name } & \multirow{2}{*}{ Length (m) } & \multicolumn{11}{|c|}{ Sub-criteria coefficient } & \multirow{2}{*}{$\begin{array}{l}\text { Priority } \\
\text { Score }\end{array}$} \\
\hline & & & a1 & a2 & a3 & b1 & b2 & b3 & $\mathrm{c} 1$ & $\mathrm{c} 2$ & c3 & d1 & $\mathrm{d} 2$ & \\
\hline 1 & Tukad Bindu & 40.50 & - & 1.00 & 1.00 & 1.00 & 1.00 & 0.52 & 1.00 & - & - & 0.77 & 0.86 & 57.83 \\
\hline 2 & Tukad Penatih & 50.00 & - & 1.00 & 1.00 & 1.00 & 1.00 & 0.52 & 1.00 & - & - & 0.77 & 0.86 & 57.83 \\
\hline 3 & Tukad Ayung & 50.00 & - & 1.00 & 1.00 & 1.00 & 1.00 & 0.52 & 1.00 & - & - & 0.77 & 0.81 & 57.14 \\
\hline 4 & $\begin{array}{l}\text { Tukad Mati (Jl. } \\
\text { Gatsu Barat) }\end{array}$ & 20.50 & 0.20 & - & - & 1.00 & 1.00 & 0.44 & 1.00 & - & - & 0.58 & 1.00 & 50.32 \\
\hline 5 & Tukad Petangen & 10.10 & 0.20 & 1.00 & - & - & - & 0.90 & 1.00 & - & - & 0.58 & 0.61 & 46.09 \\
\hline 6 & Tukad Kuta & 31.00 & - & 1.00 & - & - & - & 0.36 & 1.00 & 1.00 & 1.00 & 1.00 & 0.14 & 45.27 \\
\hline 7 & Tukad Penet & 45.00 & 0.20 & 1.00 & - & - & - & 0.86 & 1.00 & - & - & 0.52 & 0.61 & 45.21 \\
\hline 8 & $\begin{array}{l}\text { Tukad Sangsang } \\
\text { A }\end{array}$ & 50.00 & 0.40 & 1.00 & 1.00 & - & - & 0.26 & 1.00 & - & 1.00 & 0.14 & 0.16 & 45.02 \\
\hline 9 & Yeh Agung & 30.00 & 0.40 & - & 1.00 & - & - & 1.00 & - & 1.00 & 1.00 & 0.70 & 0.30 & 43.80 \\
\hline 10 & $\begin{array}{l}\text { Tukad Lembeng } \\
\text { A }\end{array}$ & 15.00 & 0.20 & 1.00 & - & 1.00 & 1.00 & 0.42 & 1.00 & - & 1.00 & 0.27 & - & 43.09 \\
\hline
\end{tabular}

Table 11 shows comparison of rank priority for bridge maintenance between existing method (based on technical condition of bridge only), realized bridge maintenance program and based on AHP method. It can be seen that the results of bridge maintenance priority based AHP method is very close to the realized program (62.5\% similar projects). However when calculated based on the existing method, the similarity is $0 \%$. Therefore, by considering several criteria included in this study, the AHP method was proven to be able to be applied in preparing the bridge maintenance priority for national road in Bali Province.

Table 11: Comparison of rank priority for bridge maintenance in Bali Province

\begin{tabular}{llll}
\hline Rank & $\begin{array}{l}\text { Existing method (based on } \\
\text { the technical condition only) }\end{array}$ & Realized program & AHP method \\
\hline 1 & Tukad Mati II & Tukad Bindu & Tukad Bindu \\
\hline 2 & Tukad Sangsang A & Tukad Penatih & Tukad Penatih \\
\hline 3 & Tukad Biaung B & Tukad Ayung & Tukad Ayung \\
\hline 4 & Tukad Muntur A & Tukad Udang-udang A & Tukad Mati (Gatsu Barat) \\
\hline 5 & Tukad Lembeng B & Tukad Mati (Gatsu Barat) & Tukad Petangen \\
\hline 6 & Yeh Agung & Tukad Lembeng A & Tukad Kuta \\
\hline 7 & Tukad Gunung Sari & Tukad Panti A & Tukad Penet \\
\hline 8 & Pangkung Batu Mangsel I & Tukad Cekatung & Tukad Sangsang \\
\hline 9 & & & Yeh Agung \\
\hline 10 & & & Tukad Lembeng A \\
\hline
\end{tabular}




\section{CONCLUSION}

Many countries in particular developing country like Indonesia have faced with the limited fund available to maintain bridges. In order to prioritize bridge maintenance in Bali Province, a multi-criteria decision making approach based on the Analytic Hierarchy Process (AHP) was applied. It was found that the stakeholders for bridge maintenance in Bali Province gave priority to road network system criteria followed by movement system, land use system and then institutional system. The main criteria in determining bridge maintenance priority was bridge condition, followed by road narrowing, transportation strategic area, traffic volume, bridge function, bridge maintenance history, socio-cultural strategic area, tourism strategic area, bridge material, budget allocation and the inclusion in the strategic planning. By comparing between existing method (based on technical condition of the bridge only), realized bridge maintenance program and based on AHP method, it was found that the results of bridge maintenance priority based on the AHP method is very close to the realized program (with $62.5 \%$ similar projects), while the similarity of the existing method is $0 \%$. Therefore, by considering several criteria, the AHP method was proven to be able to be applied in preparing the bridge maintenance priority program for national road in Bali Province. The findings of this study suggested that as many aspects influenced the bridge maintenance program, a multi-criteria approach needs to be used to prepare the prioritization program of the bridge maintenance. The methodology proposed can be used by Department of Public Work to rank the bridges to be maintained in the future.

\section{ACKNOWLEDGEMENT}

The authors would like to thank to the Research and Community Service for Prosperity of Udayana University for financially supporting this research.

\section{REFERENCES}

[1] M. Liu, V. Balali, H.H. Wei and F.A.P. Mora, Scenario-based multi-criteria prioritization framework for urban transportation projects, American Journal of Civil Engineering and Architecture, vol. 3 no. 6, pp. 193-199, 2015. Available online at http://pubs.sciepub.com/ajcea/3/6/1 @ Science and Education Publishing DOI:10.12691/ajcea-36-1.

[2] A. Deluka, B. Karleuša, and N. Dragičević, Review of multicriteria-analysis methods application in decision making about transport infrastructure, Gradevinar, vol. 65, no. 7, pp. 619-631, 2013.

[3] I.C. Schutte and A. Brits, Prioritising transport infrastructure projects: towards a multi-criterion analysis, Southern African Business Review, vol. 17, no. 3, pp. 97-117, 2012.

[4] D. Tsamboulas, G.S. Yiotis and K.D. Panou, Use of multicriteria methods for assessment of transport projects, Journal of Transportation Engineering, vol. 125, no. 5, pp. 407-414, 1999.

[5] J. Niksa, K. Snjezana and B. Zoran, Support concept for urban road infrastructure management. Croatian Operational Research Review (CRORR), vol. 1, pp. 74-82, 2010.

[6] A. Aldian, and M.A.P. Taylor, A consistent method to determine flexible criteria weights for multicriteria transport project evaluation in developing countries, Journal of the Eastern Asia Society for Transportation Studies, vol. 6, pp. 3948-3963, 2005.

[7] R.R. Kvaraciejiene, R. Apanaviciene and A. Butauskas, Evaluation of road investment project effectiveness, Inzinerine Ekonomika-Engineering Economics, vol. 21, no. 4, pp. 368-376, 2010.

[8] K. Nosal and K. Solecka, Application of AHP method for multi-criteria evaluation of variants of the integration of urban public transport, Transportation Research Procedia 3, pp. 269-278, 2015.

[9] J. Zak and M. Kruszynski, Application of AHP and ELECTRE III/IV methods to multiple level, multiple criteria evaluation of urban transportation projects, Transportation Research Procedia 10, pp. 820-830.

[10] G. Sathya and R. Velkennedy, Selection of urban transport system by using Analytical Hierarchy Process for Madurai City, International Journal of Science Technology and Management, 4(1), pp. 483-488, 2015.

[11] A.D. Tibljas, B. Karleusa, S. Surdonja and N. Dragecevic, Use of AHP multi-criteria method for transportation infrastructure planning, Proceedings of International Scientific Conference, People, Building and Environment, Kromeriz, Czech Republic, pp. 123-134, 2014.

[12] D. Geneletti, Multicriteria analysis to compare the impact of alternative road corridors: a case study in northern Italy, Impact Assessment and Project Appraisal, vol. 23, no. 2, pp. 135-146, 2012.

[13] R. Sarrazin and Y. De Smet, Solving a multicriteria road design problem: a practical example, Multiple Criteria Decision Making: Application in Management and Engineering, Springer International Publishing, Switzerland, 2017.

[14] J. Sara, R.B. Stikkelman and P.M. Herder, Assessing relative importance and mutual influence of barriers for CCS deployment of the road project using AHP and DEMATEL methods, International Journal of Greenhouse Gas Control, Vol. 41, pp. 336-357.

[15] D.N. Utama, M.D. Saputra, L.N. Wafiroh, M.A. Putra and P. Lestari, F-multicriteria based decision support system for road repair and maintenance (case study: three areas in Tangerang Selatan, Province Banten, Indonesia). International Journal of Management and Applied Science, 2(10), pp. 171-175, 2016. 
[16] E. Noorzai, K.G. Jafari, R. Heshmatnezhad and B. Vahedi, Implementing AHP approach to select an appropriate financing method for PPP highway projects in Iran, International Journal of Structural and Civil Engineering Research, 3(1), pp. 67-73, 2016.

[17] C. Qin and Y. Zhang, Evaluation of the safety on mine road based on fuzzy analytic hierarchy process, Journal of Transportation Technology, 7, pp. 70-82, 2017.

[18] W. Fangwen and X. Chengfeng, Durability of reinforced concrete arch bridge based on Fuzzy Analytic Hierarchy Process Method, The Open Civil Engineering Journal, 9, pp. 888-895, 2015.

[19] M. Rashidi, M. Ghodrat, B. Samali, B. Kendall and C. Zhang, Remedial modelling of steel bridge through application of Analytical Hierarchy Process (AHP), Applied Science, 7(168), pp. 1-20, 2017.

[20] C.L. Hwang and K. Yoon, Multi attribute decision making - an introduction, Sage University Papers, Sage Publications, 1995.

[21] T.L. Saaty, The Analytic hierarchy process, $1^{\text {st }}$, Great Britain:University of Pittsburgh, 1986.

[22] T.L. Saaty, How to make decision: the Analytic Hierarchy Process, Interfaces, vol. 24, no. 6, pp. 19-43, 1994. 